\title{
Restraining The Dissolution Of Faltering Exchange Relationships: The Influence Of Relationship Trust And Switching Barriers On Customer Complaining, Loyalty, And Defection
}

\author{
Manfred F. Maute, (E-mail:maute@unbc.ca), University of Northern British Columbia
}

\begin{abstract}
Notwithstanding the advantages conferred by relational exchange, few buyer-seller relationships survive changes in the needs, expectations, or satisfaction levels of exchange partners indefinitely. In order to investigate the role that barriers play in restraining relationship dissolution after a service failure, a relationship dissolution model in which relationship trust and switching barriers are represented as exogenous predictors of relationship dissolution behaviors was developed and tested. Results suggest that switching barriers, and to a lesser extent relationship trust, influenced customer complaining, loyalty, and defection following a core service failure. However, when sellers restrained relationship dissolution by imposing economic costs on buyers, longer-term customer loyalty was reduced. Theoretical and managerial implications of these findings are discussed.
\end{abstract}

\section{Introduction}

ncreasing competition has prompted many firms to cultivate collaborative exchange relationships with
suppliers and customers (Estelami, 2000; Doney and Cannon, 1997). Research suggests that relational
exchange reduces conflict, increases efficiency, and enhances relationship commitment for suppliers (see Geyskens et al., 1998). Despite conceding the opportunity to play suppliers off against each other, customers derive economic, social, and emotional benefits from relational exchange (Gwinner et al., 1998). Few relationships, however, survive changes in the needs, expectations, or satisfaction levels of exchange partners indefinitely. Moreover, the dissolution of relational exchange is costly and time consuming, involving as it does the unraveling of complex economic, emotional, and social ties (Dwyer et al., 1987). Yet, relatively little is known about how partners disengage from relational exchange or what factors influence the dissolution of collaborative exchange relationships.

Building on earlier research by Morgan and Hunt (1994) and Guiltnan (1989), a model of exchange relationship dissolution in which relationship trust and switching barriers are represented as exogenous predictors of several relationship dissolution behaviors is developed and tested. While seller dissatisfaction could prompt relationship dissolution, we focus on disengagement by buyers, a more common phenomenon in consumer markets. The stimulus for relationship decline is represented as a core service failure, a pivotal event in any exchange relationship that undermines confidence in the exchange partner, elicits strong affective responses from aggrieved buyers, and compromises the value of future exchange.

Readers with comments or questions should contact the author via email. 


\section{Background}

Dwyer, Schurr and Oh (1987) describe relationship elaboration as a four-stage process that culminates in mutual dependence between highly committed buyers and sellers. Relationship trust is defined as the extent to which one exchange partner believes the other to be honest and benevolent (Doney and Cannon, 1997. Trust is conceived here as an emotional attachment between exchange partners that functions as a psychic barrier to relationship change. Although relationship elaboration and dissolution appear to unfold in distinctly different ways (Baxter and Philpot, 1982), a similar role is ascribed to trust in both processes. During relationship elaboration, trust delays the premature development of interdependence between exchange partners of unproven integrity and reliability (Morgan and Hunt, 1994). Correspondingly, by permitting exchange partners to look beyond the immediate consequences of a faltering relationship to the future value of exchange, trust is theorized to restrain relationship dissolution.

Switching barriers impose economic costs on exchange partners when a relationship is terminated. Guiltnan's typology of switching barriers (1989) comprises various economic costs associated with contractual obligations, relationship set-up, and relationship continuity. Hirschman (1970) described 'severe initiation' and/or 'high penalties for exit' enacted by sellers to defend their markets against changing buyer needs, variety seeking, and the marketing activities of competitors (Estelami, 2000). Whereas the barriers discussed by Guiltnan and Hirschman are examples of costs that exchange partners impose on each other, switching barriers can also arise naturally from the mutual dependence that accompanies relationship elaboration. Buyers and sellers who integrate information systems to reduce delivery times and transaction costs, for example, confront switching barriers that neither partner imposed on the other, but deter disengagement from the relationship nonetheless. In the aftermath of a service failure, switching barriers offer buyers a compelling economic reason to maintain an under performing relationship, as the cost for seeking an alternative exchange opportunity may exceed the cost of maintaining an imperfect relationship with an under performing seller.

The effect of relationship trust and switching barriers is modeled on three outcomes that bear directly on relationship dissolution. Complaining, also referred to as 'voice' by Hirschman (1970, pg. 13), is conceived as an active and constructive response to relationship decline that involves "attempts to change the practices, policies, or outputs of the organization from which one buys ...". Even though it does not pose an immediate threat to relational exchange, complaining is investigated as an affectively and economically charged response that involves not only a dissatisfaction judgment, but also a calculation about the service failure costs borne by the buyer and the potential for redress.

Exchange partners can also 'suffer in silence, confident that things will get better', a response that Hirschman refers to as 'loyalty' (1970, pg. 38). In contrast with complaining, loyalty is a passive and constructive response to dissatisfaction that has not been extensively researched, nor is particularly well understood. Defection occurs when individuals "disassociate themselves from the object of their dissatisfaction" (Hirschman, 1970, pg. 29). An active and destructive response to relationship decline, defection implies that one or both exchange partners intend to abandon the current relationship in favor of alternative exchange opportunities.

\section{Modeling Relationship Dissolution}

Relationship dissolution is conceptualized as a process in which exchange partners wind down involvement in a relationship over time and in response to events that compromise the value of future exchange. In the absence of longitudinal data that captures individual customer reactions to the evolution of an exchange relationship over time, causal paths among endogenous dissolution behaviors are modeled with cross sectional data to identify patterns of responses among active/constructive (e.g., complaining), passive/constructive (e.g., loyalty), and active/destructive responses (e.g., defection) to relationship decline. Since a core service failure may be interpreted by some buyers as creating irrevocable harm to the value of future exchange, a direct causal path from complaining to relationship dissolution is included in the model.

Much like the distinction between affective and calculative commitment (see Geyskens et al., 1998), relationship trust and switching barrier effects are discriminated by whether affective (e.g., psychic) or economic costs are im- 
posed on exchange partners who seek to terminate a relationship. Relationship trust and switching barriers are represented as exogenous predictors of relationship dissolution behaviors driven by affect in the first instance and economic costs in the second. Thus, relationship trust is hypothesized to be positively related to constructive responses to relationship decline such as complaining and loyalty that are driven by affect. Contrastingly, switching barriers are hypothesized to be related to active responses like complaining and exit that are driven by the costs associated with relationship contracts, setup, and continuity. The effect of trust on defection is hypothesized to be indirect, operating through loyalty, and thereby obviating the need for a direct causal path between switching barriers defection.

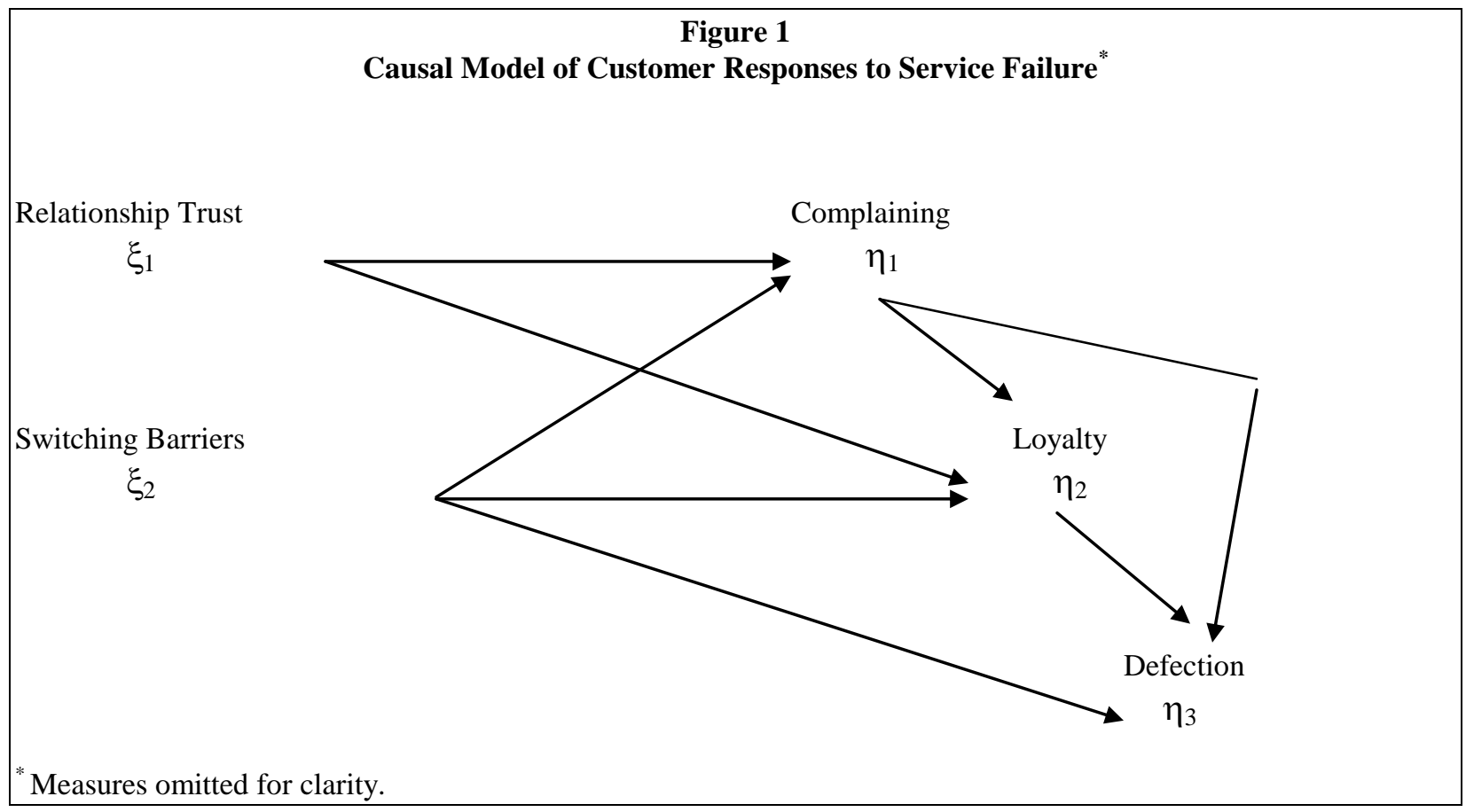

\section{Method}

Twelve hundred homeowners who had recently listed residential properties for sale with a real estate service in a southeastern city were mailed a cover letter, questionnaire, and two follow-up post cards. Discounting thirtyfive undeliverable questionnaires, 354 usable replies were received within eight weeks, ensuring a response rate of thirty-one percent. No significant differences between respondents and non-respondents in terms of residential zip code, listing date, or value of the listing were observed.

A one-page description of a core real estate service failure was embedded in each questionnaire. In this description, homeowners were represented as buyers of a real estate service contracted for with a real estate agent. Service failure was operationalized as the agent's inability to generate a successful offer for the home during the period when the service contract was in effect. After reading the scenario, participants were asked to respond to a series of questions about the event. Research suggests that mental simulation represents a valid approach to the measurement of individual-level responses to consumption experiences (see Smith \& Bolton, 1999), minimizing situational biases that are known to influence attribution judgments, response biases due to pre-existing affective states, and social desirability effects that can bias self-reports about interpersonal relationships (see Wilson and Brekke 1994). 


\section{Results}

The model was estimated with LISREL VIII (see Table 1 for correlation matrix). Constructs were measured with single indicators and scales of measurement were fixed by setting loadings for the $\Lambda_{\mathrm{x}}$ and $\Lambda_{\mathrm{y}}$ matrices to 1.0 and fixing errors in the diagonals of the $\Theta \varepsilon$ and $\Theta_{\delta}$ matrices equal to 10 percent of the indicator's variance (see Hayduk, 1987). Minor re-specification of the model was undertaken to improve fit by introducing a path from switching barriers to loyalty based on analysis of modification indexes. The re-specified model provided a good fit to the data as indicated by a non-significant chi square $\left(\chi_{3}^{2}=6.21, \underline{p}<.102\right)$, an RMSE value of .055 , and fit indices in excess of .95 (GFI = .99; $\mathrm{AGFI}=.97)$.

\begin{tabular}{|c|c|c|c|c|c|c|}
\hline \multicolumn{7}{|c|}{$\begin{array}{c}\text { Table } 1 \\
\text { Correlation Matrix }^{*}\end{array}$} \\
\hline & Barriers & & Trust & Complain & Loyalty & Defection \\
\hline Barriers & 3.23 & & & & & \\
\hline Trust & -.469 & & 2.22 & & & \\
\hline Complain & .547 & - & .375 & 2.97 & & \\
\hline Loyalty & -.471 & & .433 & -.311 & 3.52 & \\
\hline Dissolution & .270 & & -.429 & .168 & -.520 & 3.40 \\
\hline
\end{tabular}

Structural parameters are summarized in Table 2. Results indicate that switching barriers were a significant deterrent to relationship dissolution following a service failure affecting all three dissolution behaviors. Switching barriers increased complaining $\left(\gamma_{12}=.75, \underline{\mathrm{p}}<.01\right)$, and decreased defection $\left.\gamma_{32}=-.51, \underline{\mathrm{p}}<.001\right)$. Unexpectedly, switching barriers also decreased loyalty $\left(\gamma_{22}=-.47, \underline{p}<.001\right)$. The effects of relationship trust were less pronounced in magnitude and more limited in scope. Trust was negatively related to loyalty $\left(\gamma_{21}=.21, p<.001\right)$ and positively, but not significantly, associated with complaining.

Table 2

Structural Parameters Relationship Dissolution Model

Structural Parameter

Trust

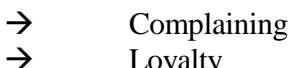

$\rightarrow \quad$ Loyalty

Switching Barriers

$\begin{array}{lll}\text { Barriers } & \rightarrow & \text { Complainin } \\ & \rightarrow & \text { Loyalty } \\ & \rightarrow & \text { Defection } \\ & & \\ \text { Complaining } & \rightarrow & \text { Loyalty } \\ & \rightarrow & \text { Defection } \\ \text { Loyalty } & \rightarrow & \text { Defection }\end{array}$

${ }^{\mathrm{a}} \mathrm{T}$ Value; $* * \mathrm{p}<.01 ; * * * \mathrm{p}<.001$

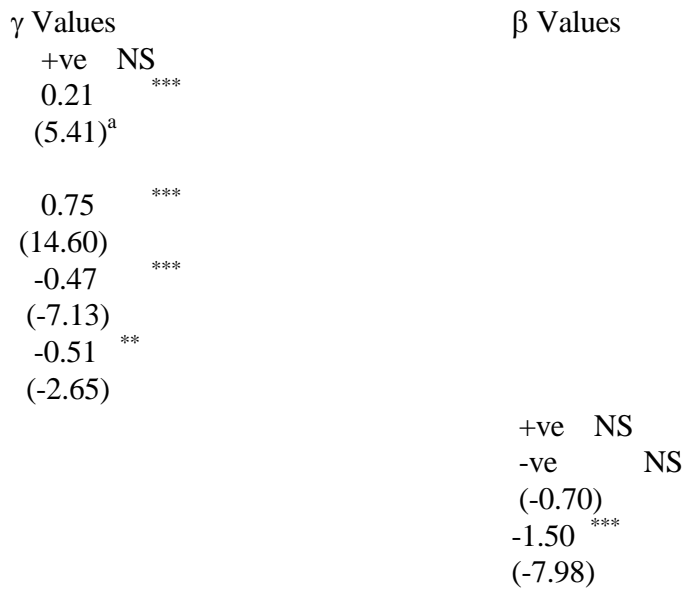

$(-7.98)$ 
Only a one causal path among the endogenous constructs was statistically significant. Loyalty decreased defection $\left(\beta_{32}=-0.70, p<.001\right)$, but while complaining had a positive effect on loyalty and a negative effect on defection as hypothesized, neither of these effects was significant at the .10 level.

\section{Discussion}

The elaboration of collaborative exchange relationships has attracted considerable research interest in marketing, even though few relationships achieve the level of mutual dependence characteristic of relational exchange and even fewer endure for prolonged periods of time. A model of exchange relationship dissolution was developed and tested to investigate the role that psychic and economic costs play in restraining relationship dissolution after a service failure. In a manner reminiscent of relationship elaboration, switching barriers, and to a lesser extent, relationship trust restrained the dissolution of faltering exchange relationships. Switching barriers increased complaining, reduced defection, and unexpectedly, also decreased loyalty. Relationship trust increased loyalty, but had no significant effect on complaining. Observed structural paths among endogenous constructs were largely nonsignificant. Loyalty had a strong negative effect on relationship dissolution but findings for complaining were inconclusive, as the structural coefficients linking complaining to loyalty and defection were not statistically significant.

These findings suggest that building buyer loyalty is one way that sellers can strengthen exchange relationships to weather adverse events like service failures. However, potential for converting buyer complaining into a relationship building exercise described by some researchers (see, for example, Estelami, 2000) is not reflected in these results. Complaining emerged as an isolated dissolution behavior that was unrelated to loyalty or defection. This may be because when relationship decline is stimulated by a core service failure rather than some other event, the natural tendency may be for buyers to seek redress whether or not they ultimately intend to dissolve the exchange relationship. Nevertheless, one important implication of the lack of statistically significant associations between complaining and other dissolution behaviors is that while complaining seems unlikely to lead to further decline in a faltering exchange relationship, the effective handling of customer complaints neither convincingly builds loyalty to the seller, nor reduces customer intentions to defect.

With limited opportunities for sellers to exploit natural associations among different dissolution behaviors, the necessity to leverage psychic and economic barriers to relationship dissolution takes on even greater importance. There was some support for anticipated distinctions between the effects of psychic barriers (e.g., trust) on constructive behaviors and economic barriers (e.g., switching barriers) on active behaviors. However, trust was not related to complaining, and the effects of switching barriers were disproportionately pervasive and powerful so as to influence not only active responses such as complaining and defection, but also loyalty.

Perhaps because service failures are bitter experiences for loyal customers that badly compromise beliefs in the seller's integrity and reliability, the effect of relationship trust was confined to loyalty. Moreover, while trust increased loyalty, the magnitude of the effect as reflected in the standardized structural coefficient $\left(\gamma_{21}=.21\right)$ was less than half that of the negative effect of switching barriers $\left(\gamma_{22}=-.47\right)$. It appears, therefore, that imposing economic costs on buyers is an effective deterrent to termination of an exchange relationship, at least in the near term. Apparently, however, restraining the dissolution of a faltering relationship by imposing these costs cannot be achieved without the loss of loyalty. Since loyalty decreases defection, imposing switching barriers on buyers increases the future risk of dissolution even as the immediate risk posed by an event like a core service failure is reduced.

The fact that switching barriers would decrease buyer loyalty to an exchange relationship is not surprising. If relationship trust constitutes a less potent barrier to dissolution, sellers would seem to have little recourse except to rely on switching barriers while working through the inevitable problems that befall exchange relationships from time to time. However, if buyers were to perceive switching barriers more so as benefits foregone upon the termination of a relationship than costs imposed by sellers to lock them in, the strong deterrent to dissolution afforded by switching barriers could perhaps be sustained without the correspondingly negative effect on loyalty. Complaint, refund, service recovery, and service guarantee programs are examples of switching barriers founded on benefits rather than costs. Incentives such as these could be more useful in retaining patronage without arousing feelings in buyers 
that they are being asked to pay for the privilege of terminating an under performing exchange relationship.

\section{Conclusion}

Although empirical support for the relationship dissolution model was obtained, results should be interpreted cautiously for several reasons. First, even though the study employed respondents who were experienced consumers of real estate services, participants responded with introspection to a fictionalized account of a core service failure. Despite research suggesting that mental simulation is a valid methodology for theory development and testing and meticulous care in designing and pre-testing the service failure scenario, participants may not have reacted the same way to a real life event. Second, the stimulus for relationship decline was a core service failure. Thus, the observed lack of empirical association between complaining and the other dissolution behaviors may have been the result of intentions to complain by both those participants who were inclined to remain loyal and those intending to dissolve the relationship. Third, the study was conducted in a single service industry and a specialized service failure setting. Results may not be generalizable to other populations, service failure contexts, or industries.

Despite these limitations, the study makes a useful contribution to understanding how exchange relationships evolve beyond the stage of mutual dependency and commitment that has been the focus of much of the prior research on relationship elaboration. Focusing attention on causal associations among dissolution behaviors permits a clearer picture of faltering exchange relationships emerge. In addition, tracing the effects of trust and switching barriers through to dissolution behaviors makes it was possible to identify opportunities for sellers to proactively manage psychic and economic barriers so as to enhance the durability of relational exchange despite the inevitability of problems like service failures that undermine customer confidence in the seller and the value of future exchange.

\section{References}

1. Anderson, James C. and David W. Gerbing (1988), "Structural Equation Modeling in Practice: A Review and Recommended Two Step Approach," Psychological Bulletin, 103(3), 411-23.

2. and James A. Narus (1990), "A Model of Distributor Firm and Manufacturer Firm Working Partnerships," Journal of Marketing, 54(January), 42-58.

3. Bagozzi, Richard P. (1975), "Marketing as Exchange," Journal of Marketing, 39(October), 32-39.

4. $\quad$ and J. Philpott (1982), "Attribution-Based Strategies for Initiating and Terminating Relationships," Communication Quarterly, 30(Summer), 217-24.

5. Doney, Patricia M. and Joseph P. Cannon (1997), "An Examination of the Nature of Trust in Buyer-Seller Relationships, Journal of Marketing, 61(April), 35-51.

6. Dwyer, R. Robert, Paul H. Schurr, and Seji Oh (1987), "Developing Buyer-Seller Relationships," Journal of Marketing, 51(April), 11-27.

7. Estelami, Hooman (2000), "The Profit Impact of Consumer Complain Solicitation Across Market Conditions, “Journal of Professional Services Marketing, 20(1), 165-195.

8. Geyskens, Inge, Jan-Benedict E. M. Steenkamp and Nirmalya Kumar (1998), "Generalizations About Trust in Marketing Channel Relationships Using Meta-Analysis," International Journal of Research in Marketing, 15, 223-248.

9. Guiltnan, Joseph P. (1989), “A Classification of Switching Costs with Implications for Relationship Marketing.” In Marketing Theory and Practice, Eds. Childers, Terry L. and Richard P. Bagozzi, American Marketing Association Winter Educators' Conference, AMA, Chicago, IL, 216-220.

10. Gwinner, Kevin P., Dwayne D. Gremler and May Jo Bitner (1998), "Relational Benefits in Services Industries: The Customers Perspective," Academy of Marketing Science. Journal, Spring, 101-114.

11. Hayduk, Leslie A. (1987), Structural Equation Modeling with LISREL Essentials and Advances. Baltimore: The Johns Hopkins University Press.

12. Hirschman, A. O. (1970), Exit, Voice, and Loyalty: Responses to Decline in Firms, Organizations, and States. Cambridge, Mass.: Harvard University Press.

13. Klemperer, P. (1987), "Markets with Consumer Switching Costs," The Quarterly Journal of Economics, Vol. 102, 375-394. 
14. Morgan, Robert M. and Shelby D. Hunt (1994), "The Commitment-Trust Theory of Relationship Marketing," Journal of Marketing, 58(July), 20-38.

15. N'gbala, Ahogni and Nyla R. Branscombe (1995), "Mental Simulation and Causal Attribution: When Simulating an Event Does Not Affect Fault Assignment," Journal of Experimental Social Psychology, 31(March), $139-62$.

16. Westbrook, Robert A. (1987), "Product/Consumption Based Affective Responses and Postpurchase Processes," Journal of Marketing Research, 24(August), 258-70.

17. Wilson, Timothy D. and Nancy Brekke (1994), "Mental Contamination and Mental Correction: Unwanted Influences on Judgments and Evaluations," Psychological Bulletin, 116(July), 117-42.

Notes

Notes 
